\title{
FEASIBILITY OF COMPUTER VISION AS PROCESS ANALYTICAL TECHNOLOGY TOOL FOR THE DRYING OF ORGANIC APPLE SLICES
}

\author{
Roberto Moscetti ${ }^{1}$, Flavio Raponi ${ }^{1}$, Barbara Sturm ${ }^{2}$, \\ Swathi Sirisha Nallan Chakravatula ${ }^{1}$, Riccardo Massantini ${ }^{1}$ \\ ${ }^{1}$ Department for Innovation in Biological, Agro-food and Forest system \\ University of Tuscia, Via S. Camillo de Lellis snc, 01100 Viterbo, Italy \\ Email: rmoscetti@unitus.it \\ ${ }^{2}$ Process and Systems Engineering in Agriculture Group, Department of Agricultural and Bisosystems \\ Engineering, University of Kassel, Nordbahnhofstrasse 1a, 37213 Witzenhausen
}

\begin{abstract}
Usage of computer vision (CV) as Process Analytical Technology tool in drying of apple slices was tested. Samples were subjected to various anti-browning treatments at sub-and atmospheric pressures, and dried at $60^{\circ} \mathrm{C}$ up to a moisture content (dry basis) of $0.18 \mathrm{~g} / \mathrm{g} . \mathrm{CV}$-based prediction models of changes in moisture content (wet basis) were developed and promising results were obtained $\left(R^{2} P>\right.$ $0.99, R M S E P=0.01 \div 0.06$ and BIASP $<0.06$ in absolute value), regardless of the anti-browning treatment.
\end{abstract}

Keywords: image analysis; dipping treatments; vacuum impregnation; chemometrics; smart drying

\section{Introduction}

Consumers in developed countries are becoming more critical and demanding in their food choices (Grunert et al., 2005); they expect high-quality foods produced sustainably and preferably regionally. In addition, European policy pushes towards the sustainable development of the food sector through mid- and long-term goals. Up to the year 2050, food industry will face three important challenges: $(i)$ to meet the global food demand generated by a growing population (ii) to increase the sustainability of the food sector and (iii) to meet consumer expectations of quality and safety.

Processing methods that enhance food stability and retain food quality have an enormous impact in globalized market through the reduction of food losses and processing, storage, transportation and distribution costs (Moscetti et al. 2017). In this context, food drying plays a major role because it is successfully used to reduce storage and shipping costs by enabling storage at room temperature, reducing weight and packaging volume. Despite these advantages, drying is one of the most energy-intensive processes in the food industry; in fact, it potentially significantly contributes to climate change as most dryers use fossil fuels (Moscetti et al., 2018a). Moreover, drying usually requires long process cycle times and may negatively affect physicochemical and sensorial characteristics of the final product (Raponi et al., 2017; Ratti, 2001). In order to alleviate drying drawbacks, several studies were carried out over the years with the aim of increasing the process efficiency through development and optimization of $(i)$ heat recovery systems (Barbosa de Lima et al., 2015; Kemp, 2005), (ii) pre-processing methods of raw material to be dried (Lukinac, 2013) and (iii) real-time monitoring and control systems of process parameters affecting quality of the end-product (Sturm et al. 2014; Winiczenko et al., 2018). 
Among emerging drying techniques, smart drying is one of the recent and most promising one (Moscetti et al., 2018a). It enables to proactively monitor quality changes in product as well as dryer operating conditions, through an interdisciplinary approach which involves various scientific sectors, such as chemometrics (Pomerantsev and Ye, 2012), artificial intelligence (Sun et al., 2018), biomimetics (e.g. electronic nose, tongue and mucosa) and computer vision (Martynenko, 2006; Sturm et al., 2014) as well as single-point spectroscopy and hyper/multi-spectral imaging (Moscetti et al., 2018a).

Apple is the fourth most consumed commercial fruit worldwide (Aghilinategh et al., 2015) and due to the modern lifestyle, dried apple exhibits a growing trend in consumption as snacks, chips or integral breakfasts (Vega-Gàlvez et al., 2012). However, hot-air drying of apple may result in discolouration due to browning reactions (Sturm et al., 2012). Thus, pre-treatment of raw material is strictly recommended in order to produce a high-quality end-product. However, pre-treatment may affect drying kinetics and subsequently impact the modeling of thin-layer behaviour of product, which is fundamental in deciding the ideal drying conditions (i.e. equipment design, optimization and product quality improvement).

The objective of this study was to evaluate both feasibility and robustness of computer vision as Process Analytical Technology tool for modeling the drying kinetics of apple slices through the linear relationship between the changes in the relative area shrinkage and the moisture content of product during the process. In addition, samples were also subjected to various antibrowning treatments (i.e. dipping or vacuum impregnation in solution with anti-browning agents), which are mandatory for obtaining high-quality dried apple slices, with the aim of evaluating their possible effect on the drying kinetics.

\section{Material and methods}

Sound apples (Malus domestica Borkh var. Gala) at the same ripening stage were washed, peeled, decored and cut into slices of 5-mm thick and 23-mm diameter. Samples were ( $i$ ) dipped in trehalose $4 \% \mathrm{w} / \mathrm{v}(\mathrm{TR})$; trehalose $4 \% \mathrm{w} / \mathrm{v}+$ ascorbic acid $1 \% \mathrm{w} / \mathrm{v}(\mathrm{TR}+\mathrm{AA})$; and water as control (CNT) at atmospheric and subatmospheric pressure (i.e. vacuum impregnation, VI); and then (ii) dried at $60^{\circ} \mathrm{C}$ up to a final $\mathrm{MC}_{\mathrm{db}}$ of $0.18 \mathrm{~g} / \mathrm{gDW}$. Ascorbic acid was selected due to its well-known inhibition effect towards polyphenol oxidase (Albanese et al., 2007; El-Shimi, 1993). Trehalose is a natural disaccharide, generally recognised as safe (Megarry et al., 2011), used as a food ingredient and pharmaceutical excipient. It acts as an edible coating with ability to preserve colour and aroma of the dried fruits as well as reduce non-enzymatic browning occurrence (Aktas et al., 2007; Albanese et al., 2007). Finally, subatmospheric pressure (i.e. VI) was tested because of its potential in stabilizing functional properties of food and its higher capability of embedding fruit and vegetable tissues with solutes when compared with conventional dipping (Neri et al., 2016).

The relative humidity of the drying process was not controlled but measured. Treatments were carried out at $20^{\circ} \mathrm{C}$ for a dipping time of $5.25 \mathrm{~min}$, with a sample/solution ratio of 1:5 (w/w); specifically VI treatment consisted of a $0.25 \mathrm{~min}$ vacuum time and a 5 min post-vacuum time, and was achieved using a 5-L vacuum chamber connected to a vacuum pump mod. $\mathrm{N}$ 840.3 FT.18 (KNF, USA). Drying was performed using a hot-air dryer mod. Biosec (Tauro Essicatori, Italy) which was ad-hoc modified to embed a digital balance mod. HT1500 (NHU, Germany), a camera mod. EOS 400D (CANON, Japan) and a 4200K illuminant source. The drying setup was controlled using a single-board computer mod. Raspberry Pi B+ (Raspberry Foundation, UK) in combination with a self-made Jupyter Notebook (Project Jupyter, USA), which allowed $(i)$ to collect data at constant time intervals (i.e. image and weight of samples every $5 \mathrm{~min}$ and $4 \mathrm{sec}$, respectively) and (ii) to extract morphological feature of samples from each raw image (i.e. surface area of samples). The 'relative area shrinkage' was calculated according to Eq. 1: 


$$
S_{b}=\frac{S_{t}}{S_{0}}
$$

where $S_{b}$ corresponds to the 'relative area shrinkage', $S_{t}$ represents the 'surface area' in pixels at the drying time ' $t$ ', and $\mathrm{S}_{0}$ corresponds to the 'surface area' in pixels of the fresh sample. The R software v3.4.1 was used to develop linear prediction models able to relate the changes in $\mathrm{MC}_{\mathrm{wb}}$ of apple slices to the changes in relative area shrinkage during drying. Model performances were evaluated in terms of Root Mean Square Error (RMSE), BIAS and coefficient of determination $\left(\mathrm{R}^{2}\right)$ of calibration $(\mathrm{C})$ and prediction $(\mathrm{P})$.

\section{Results and discussion}

Changes in quality attributes of horticultural products during drying are successfully measurable based on their variations in spatial distribution data (i.e. size and shape information), which can be analysed through a computer vision system (Moscetti et al., 2018b). Consequently, we explored the possibilities offered by image analysis for quantifying the moisture content of apple slices as a function of change in the relative area shrinkage $\left(\mathrm{S}_{\mathrm{b}}\right)$ of product during drying. As found in literature (Aghbashlo et al., 2016), the wet-basis moisture content $\left(\mathrm{MC}_{\mathrm{wb}}\right)$ was successfully predicted using spatial information only. Thus, the additional value of the present work lays in the fact that these results underline the possibility of developing a forecast model for prediction of the drying time required by the product to reach a specific moisture content based on the past and present spatial data.

Figure 1 shows results from the regression model for the TR+AA dipping treatment (no VI), which was selected as example treatment. For all models, a BIAS issue was evident during the second falling rate drying period, i.e. when $\mathrm{MC}_{\mathrm{wb}}$ dropped below $0.1 \mathrm{~g} / \mathrm{gFW}$.
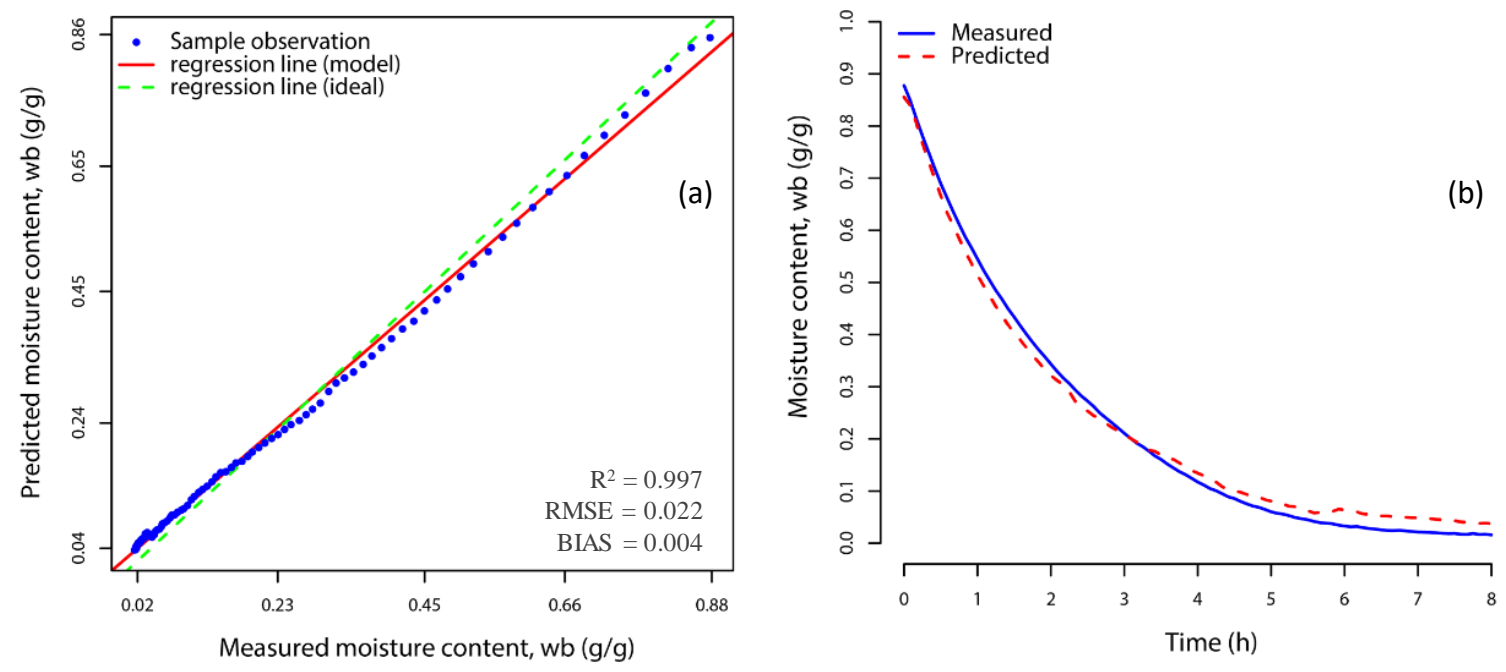

Fig. 1. Linear regression plot (a) and first-order plot (b) of measured and predicted $M C_{w b}$ values for the TR+AA dipping treatment performed at atmospheric pressure.

In general, Table 1 shows excellent results in terms of prediction capability, regardless of the anti-browning pre-treatments used. Results show a RMSEP ranging from 0.011 to 0.058 $\mathrm{g} / \mathrm{gFW}$, a BIASP lower than 0.06 in absolute value, and a $\mathrm{R}^{2} \mathrm{P}$ always higher than 0.99 . In addition, considering that the relative humidity (R.H.) of process was not controlled, it is possible to assert that all models were insensitive to the R.H. of the drying chamber.

Specifically, it is important to highlight that models computed using spatial data from samples subjected to VI had lower predicting performances and, were less robust. This is probably because apple is a highly porous product and VI may alter both porosity and texture 
in a non-systematic way (Martínez-Monzó et al., 2008). However, further research would be necessary for verification.

Table 1. Summary of performance metrics of the linear regression models.

\begin{tabular}{|c|c|c|c|c|c|c|c|}
\hline \multirow{2}{*}{ Dipping solution } & \multirow{2}{*}{$\mathrm{VI}^{\mathrm{a}}$} & \multicolumn{2}{|c|}{$\mathrm{RMSE}^{\mathrm{b}}$} & \multicolumn{2}{|c|}{ BIAS $^{c}$} & \multicolumn{2}{|c|}{$\mathrm{R}^{2 \mathrm{~d}}$} \\
\hline & & $\mathrm{C}$ & $\mathrm{P}$ & $\mathrm{C}$ & $\mathrm{P}$ & $\mathrm{C}$ & $\mathrm{P}$ \\
\hline $\mathrm{CNT}^{\mathrm{e}}$ & No & 0.009 & 0.019 & $-2.9810^{-17}$ & -0.008 & 0.998 & 0.993 \\
\hline $\mathrm{TR}^{\mathrm{f}}$ & No & 0.014 & 0.017 & $-1.1510^{-17}$ & 0.007 & 0.997 & 0.996 \\
\hline $\mathrm{TR}+\mathrm{AA}^{\mathrm{g}}$ & No & 0.008 & 0.022 & $1.5910^{-17}$ & 0.004 & 0.999 & 0.997 \\
\hline CNT & Yes & 0.008 & 0.058 & $-1.7910^{-17}$ & -0.055 & 0.999 & 0.999 \\
\hline TR & Yes & 0.010 & 0.051 & $-2.6410^{-17}$ & -0.049 & 0.998 & 0.999 \\
\hline $\mathrm{TR}+\mathrm{AA}$ & Yes & 0.005 & 0.011 & $1.3310^{-17}$ & -0.041 & 1.000 & 0.999 \\
\hline
\end{tabular}

${ }^{\mathrm{a}}$ VI: Vacuum Impregnation (Yes and No stay for sub-atmospheric and atmospheric pressure, respectively).

${ }^{b}$ RMSE: Root Mean Squared Error of calibration $(\mathrm{C})$ and prediction $(\mathrm{P})$.

'BIAS: tendency of the measurement process to over- or under-estimate the real moisture content.

${ }^{d} R^{2}$ : coefficient of determination of calibration $(C)$ and prediction $(\mathrm{P})$.

${ }^{\mathrm{e}} \mathrm{CNT}$ : control (i.e. water dipping solution).

TR: trehalose $4 \% \mathrm{w} / \mathrm{v}$ aqueous dipping solution.

'TR+AA: trehalose $4 \% \mathrm{w} / \mathrm{v}+$ ascorbic acid $1 \% \mathrm{w} / \mathrm{v}$ aqueous dipping solution.

\section{Conclusions}

In this study the feasibility of using computer vision technology as smart-drying technology, to proactively and non-destructively detect and monitor physicochemical changes (i.e. moisture content) in organic apple slices (Malus domestica Borkh var. Gala) during hot-air drying at $60^{\circ} \mathrm{C}$ was investigated. The work represents a preliminary study for the development of largescale CV-based smart drying systems.

On the basis of the results obtained, it is possible to assert that an in-line CV system embedded into a hot-air-drying unit allows to precisely measure the area of shrinkage of apple slices, and then to predict changes in $\mathrm{MC}_{\mathrm{wb}}$ of product through the linear relationship between the two parameters. VI treatment negatively affected the BIAS of the prediction model. The practical implication of this study is that modelling the data acquired during drying through computer vision can provide useful information concerning the physicochemical changes of product. Thus, the proposed approach lays the foundations for a more efficient smart dryer that can be designed, and its process optimized for drying of apple slices, reducing the human error, production cycle time, analytical time and costs.

\section{List of Acronyms and Abbreviations}
AA Ascorbic acid
BIAS Tendency of the measurement process to over- or under-estimate the real value
CNT Control (i.e. water dipping solution)
CV Computer Vision
C Calibration
DW Dry weight
FW Fresh weight
$\mathrm{MC}_{\mathrm{db}} \quad$ Dry basis moisture content
$\mathrm{MC}_{\mathrm{wb}} \quad$ Wet basis moisture content
P Prediction
PAT Process Analytical Technology 
$\mathrm{R}^{2} \quad$ Coefficient of determination

RMSE Root Mean Squared Error

$\mathrm{S}_{0} \quad$ Surface area in pixels of the fresh sample

$\mathrm{S}_{\mathrm{b}} \quad$ Relative area shrinkage

$\mathrm{S}_{\mathrm{t}} \quad$ Surface area in pixels at the drying time ' $\mathrm{t}$ '

TR Trehalose

VI Vacuum Impregnation

\section{Acknowledgements}

The authors gratefully acknowledge [1] CORE Organic Plus consortium (ERA-NET action) and MIPAAF (Ministero delle politiche agricole alimentari e forestali - Italy) for financial support through the SusOrgPlus project (D.M. 20/12/2017, n. 92350) and [2] the 'Departments of excellence 2018' program (i.e. 'Dipartimenti di eccellenza') of the Italian Ministry of Education, University and Research (MIUR) for the financial support through the 'Landscape 4.0 food, wellbeing and environment' (DIBAF department of University of Tuscia) Moreover, our sincere thanks to Gianpaolo Moscetti for the English language revision of the manuscript.

\section{References}

Aghbashlo M., Hosseinpour S., Mujumdar A.S., 2015, Application of Artificial Neural Networks (ANNs) in Drying Technology: A Comprehensive Review, Dry Technol. 33, 1397-1462.

Aghilinategh N., Rafiee S., Gholikhani A., Hosseinpur S., Omid M., Mohtasebi S.S., 2015. A comparative study of dried apple using hot air, intermittent and continuous microwave: evaluation of kinetic parameters and physicochemical quality attributes. Food Sci Nutr. 3, 519-526.

Aktas T., Fujii S., Kawano Y., Yamamoto S., 2007, Effects of pretreatments of sliced vegetables with trehalose on drying characteristics and quality of dried products. Food Bioprod Process. 85, 178-183.

Albanese D., Cinquanta L., Di Matteo M., 2007. Effects of an innovative dipping treatment on the cold storage of minimally processed Annurca apples. Food Chem. 105, 1054-1060.

Barbosa de Lima A.G., Da Silva J.V., Pereira E.M.A., Dos Santos I.B., Barbosa de Lima W.M.P., 2015, Drying of bioproducts: Quality and energy aspects. In: Drying and Energy Technologies.

El-Shimi N.M., 1993, Control of enzymatic browning in apple slices by using ascorbic acid under different conditions. Plant Foods Hum Nutr. 43, 71-76.

Grunert K.G., 2005, Food quality and safety: Consumer perception and demand. Eur. Rev. Agric. Econ. 32, 369391.

Kemp I.C., 2005. Reducing dryer energy use by process integration and pinch analysis. Dry Technol. 23, 20892104.

Lukinac J., 2013. Antibrowning Effects of Various Pretreatment Methods on Dried Apple Samples. Acta Hort. 989, 261-270.

Martynenko A.I., 2006. Computer-Vision System for Control of Drying Processes. Drying Technol., 24, 879-888.

Martínez-Monzó J., Martínez-Navarrete N., Chiralt A., Fito P., 2008. Mechanical and structural changes in apple (var. granny smith) due to vacuum impregnation with cryoprotectants. J Food Sci. 63, 499-503.

Megarry A.J., Booth J., Burley J., 2011. Amorphous trehalose dihydrate by cryogenic milling. Carbohydr Res 346, 1061-1064.

Moscetti R., Haff R.P., Ferri S., Raponi F., Monarca D., Liang P., Massantini R., 2017. Real-Time Monitoring of Organic Carrot (var. Romance) During Hot-Air Drying Using Near-Infrared Spectroscopy. Food Bioprocess Technol. 10, 2046-2059.

Moscetti R., Raponi F., Ferri S., Colantoni A., Monarca D., Massantini R., 2018a. Real-time monitoring of organic apple (var. Gala) during hot-air drying using near-infrared spectroscopy. J. Food Eng. 222, 139-150.

Moscetti R., Sturm B., Crichton S.O., Amjad W., Massantini R., 2018b. Postharvest monitoring of organic potato (cv. Anuschka) during hot-air drying using visible-NIR hyperspectral imaging. J. Sci. Food Agric. 98, 25072517.

Neri L., Di Biase L., Sacchetti G., Di Mattia C., Santarelli V., Mastrocola D., Pittia P., 2016. Use of vacuum impregnation for the production of high quality fresh-like apple products. J. Food Eng 179, 98.108.

Pomerantsev A.L., Rodionova O.Y., 2012, Process analytical technology: A critical view of the chemometricians. J. Chemom. 26, 299-310.

Raponi F., Moscetti R., Monarca D., Colantoni A., Massantini R., 2017, Monitoring and optimization of the process of drying fruits and vegetables using computer vision: a review. Sustainability 9, 1-27. 
Ratti, C. (2001). Hot air and freeze-drying of high-value foods: A review. J. Food Eng. 49, 311-319.

Sturm B., Hofacker W.C., Hensel O., 2012, Optimizing the Drying Parameters for Hot-Air-Dried Apples. Dry Technol. 30, 1570-1582.

Sturm B., Vega N., Hofacker W., 2014, Influence of process control strategies on drying kinetics, colour and shrinkage of air dried apples. Appl Therm Eng. 62, 455-460.

Sun Q., Zhang M., Mujumdar A.S. (2018). Recent developments of artificial intelligence in drying of fresh food: A review. Crit Rev Food Sci Nutr. 1-65.

Vega-Gálvez A., Ah-Hen K., Chacana M., Vergara J., Martínez-Monzó J., García-Segovia P., Lemus-Mondaca R., Di Scala K., 2012. Effect of temperature and air velocity on drying kinetics, antioxidant capacity, total phenolic content, colour, texture and microstructure of apple (var. Granny Smith) slices. Food Chem. 132, 5159.

Winiczenko R., Górnicki K., Kaleta A., Martynenko A., Janaszek-Mankowska M., Trajer J., 2018. Multi-objective optimization of convective drying of apple cubes. Comput Electron Agric. 145, 341-348. 